\title{
Study on Nursing Education Innovation and Strategies based on
}

\section{Computer Vision}

\author{
Sulan Long ${ }^{1}$ \\ ${ }^{1}$ Department of Nursing, Institute of Technology, Jiangxi University of Traditional Chinese medicine, \\ Nanchang, Jiangxi, 330004
}

KEYWORDS: Computer Vision; Nursing Education Innovation; Countermeasures

\begin{abstract}
In our country, nursing education has formed a certain scale, good momentum of development trends in the development of nursing education, the quality of training have improved significantly, but there are still several problems. Based on computer perspective nursing education, nursing education innovation problems are identified and countermeasures are also studied.
\end{abstract}

\section{Introduction}

Nursing since the Opium War with Western medicine to our country since passed, she began to thrive on the land of China. Although experienced setbacks during the Cultural Revolution, but after the reform has been considerable development. Especially since the 21 century, with the advent of the information revolution, computer is applied on innovation of nursing education, but in this process, a number of innovative nursing education problems to be solved.

\section{The Nursing Education Achievement}

Since reopening in 1983, the country returned to the University hospital admissions specialized nursing education, its size over time is also growing, continuous enrollment in advanced nursing education, nursing education also reflect the actual needs of the people. Training mode innovation and higher education in the curriculum is more scientific and reasonable. From 1996 professional nursing education reform, the more prominent features of professional nursing education and better services to the actual production and life, with the deepening of reform of nursing education, the growing of nursing personnel, to meet the needs of rapid economic development of nursing personnel. Nursing education teachers improved, forming a team with the medical knowledge and nursing content combination of professional teachers, as a steady stream of professional training of nursing personnel to improve the back-up protection.

Medicine is the final guarantee of health and the health care is a continuation of strength. As China's aging trend, improvement of people's living health requirements of the times and brought about the development of nursing education and powerful. Scientific, normative nursing education is a basic requirement and people need a health professional, scientific care to get the long-term durability.

\section{Second, the problem of educational innovation}

Times are changing, nursing education also need to keep up the pace of continuous innovation. Combined with the current era of information technology, we discuss innovation in nursing 
education from the perspective of the computer. There are several problems in nursing education innovation process.

Deep-rooted tradition of nursing education concept: many classroom College nursing education efforts to want to carve out an innovative teaching model, using the computer classroom teaching, such as PPT, books, etc., this is a new and innovative education mode, but only the knowledge to change from the textbooks on the multimedia screen, like a new name. Teachers in Nursing Education teaching process is still only pay attention to explain the theory, rather than on the students hands-on and practical ability, greatly reduce the quality of education, nursing education itself is a highly professional application categories, focusing on practice, because the traditional educational philosophy of restraint, coupled with the teachers themselves are in their own long-standing theory of teaching, which led to the students will not do, teachers do not teach embarrassment.

The old curriculum: In the information age is coming, the school to keep pace with the times and make full use of network resources for students to use computer advanced equipment for creative nursing education, this approach starting point is worth praise. But thanks to the computer teaching, many programs do not need to repeat repair school, crowded curriculum, students do not lead to a real practice time and free time. After the introduction of computer education in schools, the curriculum should be as concise as possible, take full advantage of computer teaching, allowing students to apply their knowledge, learn the real practicality of nursing skills. The old curriculum will affect the innovative ability of students, so colleges and universities should pay attention to curriculum arrangements in this regard.

Old-fashioned teaching methods: In the past teaching is indoctrination education teachers to instill the knowledge to the students, do not know the students learn how, do not know the student will not be what they have learned into practice during go with. Some teachers are good at computer teaching and nursing education will form a three-dimensional computer through the advantages of teaching, so that students understand the feelings practice. And some teachers focus on textbook knowledge, constantly instilling knowledge, the students understand difficult to digest often cause students to lose the fun of learning and the expertise is not clear. Nursing education and training Universities to innovate new teaching methods, students' ability to focus on the development and personal growth.

Lack of modern nursing education teachers: In the information age, more information needs of people with innovative nursing education. Modern nursing education personnel are required to have good knowledge of medicine, nursing knowledge and modern information technology personnel scientific and reasonable norms. To truly modern science and technology will be integrated into nursing education process going. For example, the use of three-dimensional imaging technique, the computer can be on top of the image of nursing education student, will simplify and visualize abstract problems. At the same time, teachers in the number of nursing education is also inadequate, the main reason is this aspect of nursing staff in small quantity, market demand, the salaries of teachers in insufficient wages. Therefore, to establish long-term nursing teaching mechanism will focus on training of teachers.

Innovative nursing education evaluation system is imperfect: this mainly in the evaluation system of higher education in nursing and post. In computer perspective, innovation in nursing education is particularly important, which is a breakthrough in the traditional concept and obsolete teaching methods, establish reasonable evaluation system, to highlight the application of modern teaching equipment, but also to highlight the importance of innovation. Imperfect evaluation system, often resulting in heavy theory and practice of light conditions, reasonable evaluation system to 
assign a score of scientific theory and practice, and should not only score on. Students need comprehensive training, and finally to become a comprehensive and practical aspects of nursing personnel.

\section{Third, countermeasures}

Breaking the traditional concept of nursing education process to constantly change their ideas in order to meet the age requirements for nursing education is good. New Age ideas should be innovative ideas. Perspective on the computer-based, requires educators to change the traditional concepts of education, emphasizing the practical ability, especially in nursing education, but also requires students to abandon the traditional concept, to enhance their level of practice, so that they can become innovative and comprehensive care talent. On the teaching methods, it abandons the traditional teaching concepts, content-oriented visualization, theoretical simplification, clarity of teaching, so that students in innovative nursing education high school to the real practical experience.

Improve the curriculum: the introduction of computer education in colleges and universities, you need to remove some of the excess burden of course, devote more time to the students, the more courses left to practice. To establish a rational curriculum, curriculum requirements established in line with their own students. Curriculum needs a pioneering, inventive features, and constantly optimize the course content, in line with market demand, but the reform pace many domestic universities in this regard remains slow, is not conducive to the development of nursing education, but do not help to improve the overall quality of students, reform is the motivation, nursing education also needs to reform and innovation.

Innovation teaching methods: teaching nursing education throughout the core of innovation, student-centered training model requires constant innovation of nursing education. On the way described above, the computer can change the students' interest in teaching in the classroom teaching, so that students in the course of lectures can experience the fun of practice. Teachers in the teaching process, a scientific teaching methods, abandon past indoctrination teaching, devote more time to the students, for students to find their own learning problems, develop students' ability to think independently, innovative students the ability to fully develop, so not only can improve the quality of teaching can improve students' ability to learn.

The importance of high-quality training of qualified personnel: nursing education in cultivating innovative information technology is required to meet under the requirements of the times but also the overall development. In the perspective of a computer, constantly cultivate high quality nursing talents. Combining the advantages of the Internet, high-quality personnel should fully combine their strengths active introduction of foreign advanced nursing education model and with the country's educational model fit and training of qualified personnel.

Improve the reasonable evaluation system: reasonable evaluation system should be comprehensive and targeted. In nursing education, we should focus on innovative educational evaluation standards, allowing students to become the main evaluation, so that innovation has become a key point of evaluation, highlighting the focus of nursing education innovation.

\section{Conclusion}

Nursing Education Teaching those problems need to continue to improve, steady progress in the reform, promote innovation and development of nursing education. Also requires teaching by 
combining the times, in line with the times, actively innovation, so steady advance nursing education.

\section{Acknowledgements}

Project: This paper is funded by Jiangxi 2013 Social Science 12th 5-Year Plan Project

Project No. 13JY52

\section{References}

[1] Wu Qian. Undergraduate Nurses Common Problems and Solutions [D]. In Clinical Nursing Practice. Bengbu Medical College, 2014.

[2] Luo Yi, Zhu Guojun Wang Jianping,. Undergraduate Nursing Education Problem Facing China and Countermeasures [J]. Chinese Journal of Social Medicine, 2012,02: 92-94.

[3] Liu Min, Yue Jinfeng. Our Higher Nursing Education Problems and Countermeasures [J]. Value Engineering, 2011,07: 211-212.

[4] Li Chunrong, Zhu Hui. Nursing Education Innovation Problems and Countermeasures [J]. Qilu Nursing, 2006,19: 1927-1928. 